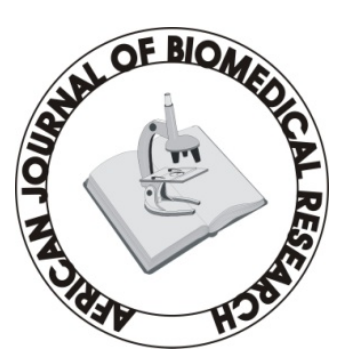

Full-text available at http://www.ajbrui.com http://www.bioline.br/md http://www.ajol.com

Received:

September 2007

Accepted (Revised): June 2008

Published

September 2008
Full Length Research Article

\section{Review of Paediatric Neurological Conditions Seen in the Physiotherapy Department of a Children's Hospital in Ibadan, Nigeria}

\author{
Peters G.O, Adetola A. and Fatudimu M.B
}

*Department of Physiotherapy, College of Medicine, University of Ibadan, Ibadan.

\begin{abstract}
Management of paediatric neurological conditions involves a multidisciplinary team approach with Physiotherapy being an important member of the team. This study investigated the proportion that neurological conditions accounted for of the total number of paediatric conditions managed at the Physiotherapy Department of the Oni Memorial Children Hospital, Ibadan between January 2004 and December 2006 and also reviewed the specific neurological conditions. Records of all the patients managed during the study period reviewed were identified from which the neurological cases were sorted out and data on specific diagnosis, age and gender were collated. A total of 546 paediatric cases were reviewed out of which 471 (86.3\%) were neurological cases with mean age of $25.3 \pm 25.2$ months and a 1.3: 1.0 male to female ratio. Cerebral palsy $\{\mathrm{CP}\}$, predominantly the spastic quadriplegic type, accounted for majority (43.7\%) of cases. Traumatic sciatic nerve palsy was the cause of physiotherapy attendance in $35.5 \%$ of cases while Obstetric brachial plexus injury accounted [10.8\%) of cases. Other conditions were Central Nervous System Infections, Down's syndrome and Paralysis of unspecified diagnosis, Radial and Facial nerve palsies and Gullian Barre syndrome. A case is made for the deployment of more resources (funds, facilities and health personnels) for the care of neurological paediatric conditions.
\end{abstract}

(Afr. J. Biomed. Res. 11: 281 - 284)

Key word: Pediatrics, Physiotherapy, Prevalence, Review, Neurological conditions.

*Address for Correspondence: teetoe262003@yahoo.com

Abstracted by:

African Index Medicus (WHO), CAB Abstracts, Index Copernicus, Global Health Abstracts, Asian Science Index, Index Veterinarius, Bioline International , African Journals online 


\section{INTRODUCTION}

Children with neurological conditions often require a rehabilitation team approach for optimum care (Logigian, 1989). According to the Royal College of Paediatrics and Child Health (2004), the Paediatric Physiotherapist is a core member of the multidisciplinary rehabilitation team. Neurological conditions arise from pathological changes or lesions of the peripheral and central nervous system that often lead to impaired movement and abnormal muscle tone (Edwards, 2001) and children with these and other sequelae of neurological conditions benefit from Physiotherapy (Michaud, 2004). Paediatric Neurological conditions include cerebral palsy, spina bifida, anterior poliomyelitis, peripheral nerve lesions and post viral polyneuropathies (Thomson et al 1999).

Cerebral palsy is the most frequent diagnosis of children who receive physiotherapy (Hayes et al, 1999). Polio paralysis and cerebral palsy accounted for $71 \%$ of physically impaired children managed at a physiotherapy clinic in Pakistan (Miles and Frizzel, 1990). Children who have suffered meningitis and cerebral malaria also experience neurological sequelae for which physiotherapy is required (Lebel and McCracken, 1989). In a review of cases of Acute Flaccid Paralysis (AFP) managed in a Physiotherapy clinic of a Nigerian tertiary hospital, sciatic nerve palsy accounted for $72 \%$ of cases [Hamzat and Omotade, 2006). Although the important role of physiotherapy in the overall management of children with neurological conditions have been reported (Steyer - Acevedo, 1994; Michaud, 2004) and the conditions that constitute the majority of cases seen by physiotherapists in some parts of the world are documented [Hayes et al, 1999, Miles and Frizzel, 1990), what obtains in a Nigerian physiotherapy clinic was considered to be important and relevant, and was therefore investigated. This 3 year $(2004$ - 2006) clinical review was carried out to investigate the paediatric neurological conditions managed at the Physiotherapy Department of the Oni Memorial Children Hospital (OMCH), Ibadan, Nigeria. The specific neurological conditions and some demographic variables of the children who presented with the conditions were studied.

\section{MATERIALS AND METHODS}

This study was conducted at the Oni Memorial children Hospital (OMCH), Ibadan, Oyo State, Nigeria. The hospital, established in 1985,is the only state government owned children Hospital that provides health care services to children in Oyo State. The Physiotherapy attendance register and records of all children seen at the Physiotherapy Department of the Oni Memorial Children Hospital between January 2004 and December 2006 were retrieved. The following data from the records was entered into a spreadsheet: Hospital number, specific diagnosis, age and gender. Data were analyzed using descriptive statistics of mean and standard deviation, range and percentages, and the frequency distributions of the various data were calculated and presented in tables.

\section{RESULTS}

Five hundred and forty-six paediatric patients were managed at the Physiotherapy Department of the Oni Memorial Children Hospital between January 2004 and December 2006. Of this number, 471 (86.3\%) presented with neurological conditions with a male: female ratio of 1.3: 1.0, mean age of $25.3 \pm 25.2$ months and age range of 10 days to 9.6 years. Gender distribution for each condition is presented in Table 1. Cerebral palsy, predominantly the spastic quadriplegic type was the most prevalent $(43.7 \%)$ cause of physiotherapy attendance. Table 2 shows frequency distribution of the types of cerebral palsy. Traumatic sciatic nerve palsy accounted for $35.5 \%$ of cases. Central Nervous System Infections accounted for 27 (7.6\%) of cases and comprised of meningitis, Poliomyelitis, Measles and Tetanus (Table 3). Down's syndrome accounted for $2.2 \%$ of all cases while only one case of Guillian Barre syndrome was managed during the period reviewed. 
TABLE 1

Gender distribution of Paediatric Neurological Conditions [N=471]

\begin{tabular}{lcccccc}
\hline \multicolumn{1}{c}{ Conditions } & Total Number n & Total \% & \multicolumn{2}{c}{ Male } & \multicolumn{2}{c}{ Female } \\
\hline Cerebral palsy & & & $\mathrm{n}$ & $\%$ & $\mathrm{~N}$ & $\%$ \\
\hline Obstetric Brachial Plexus Injury & 206 & 43.7 & 116 & 56.3 & 90 & 43.7 \\
\hline Traumatic Sciatic Nerve Palsy & 51 & 10.8 & 29 & 56.9 & 22 & 45.0 \\
\hline CNS Infections & 222 & 35.5 & 92 & 55.0 & 75 & 45 \\
\hline Down's syndrome & 27 & 5.7 & 18 & 66.7 & 9 & 33.3 \\
\hline Paralysis of unspecified diagnosis & 10 & 2.2 & 5 & 50.0 & 5 & 50 \\
\hline Radial Nerve Palsy & 5 & 1.1 & 2 & 40.0 & 3 & 60.0 \\
\hline Facial Nerve Palsy & 2 & 0.4 & 1 & 50.0 & 1 & 50.0 \\
\hline GBS & 2 & 0.4 & - & - & 2 & 100 \\
\hline
\end{tabular}

Table 2: Types of cerebral Palsy

\begin{tabular}{lcc}
\hline \multicolumn{1}{c}{ Types } & $\mathbf{N}$ & $\mathbf{\%}$ \\
\hline Spastic Quadriplegia & 95 & 46.1 \\
\hline Spastic Diplegia & 11 & 5.3 \\
\hline Spastic Hemiplegia & 37 & 18.0 \\
\hline Athethoid & 2 & 1.0 \\
\hline Hypotonic & 34 & 16.5 \\
\hline Ataxic & 2 & 1.0 \\
\hline Mixed & 5 & 2.4 \\
\hline Normal tone & 9 & 4.4 \\
\hline Unknown & 11 & 5.3 \\
\hline Total & $\mathbf{2 0 6}$ & $\mathbf{1 0 0}$ \\
\hline
\end{tabular}

Table 3: Types of CNS Infections [N= 27]

\begin{tabular}{lcc}
\hline \multicolumn{1}{c}{ Types } & n & \% \\
\hline Cerebrospinal meningitis & 11 & 40.7 \\
\hline Poliomyelitis & 8 & 29.6 \\
\hline Measles & 6 & 22.2 \\
\hline Tetanus & 2 & 7.5 \\
\hline Total & $\mathbf{2 7}$ & $\mathbf{1 0 0}$ \\
\hline
\end{tabular}

\section{DISCUSSION}

Paediatric Neurological conditions like other neurological conditions are associated with motor impairments including muscle weakness, abnormal muscle tone, decreased joint range of motion, and decreased balance and coordination and benefit from physiotherapy. The result of this study revealed that neurological conditions were most prevalent constituting $86.3 \%$ of all the cases seen over the study period. This is however contrary to the findings of Al-Naquib (1988) which showed that neurological problems accounted for $5 \%$ of pediatric consultations in Riyadh, Saudi Arabia.

Cerebral palsy was the commonest (43.7\%) condition responsible for physiotherapy attendance. This correlates with the findings in Pakistan, [Milles and Frizzle, 1990] and Riyadh [Al Naquib, 1998]. Furthermore, spastic quadriplegia was found to be the most common type of cerebral palsy contrary to the high prevalence of spastic diplegia reported in other studies [Al Naquib, 1998; Styler-Acevedo, 1994].

Traumatic sciatic nerve palsy was recorded to be the second most prevalent condition. This corresponds with the findings of Hamzat and Omotade (2006) in which sciatic nerve palsy accounted for majority (72\%) of cases of acute flaccid paralysis seen among paediatric physiotherapy patients in the University College Hospital, Ibadan. All the cases observed in our study resulted after administration of gluteal intramuscular injection. This findings lends credence to the submission of Hamzat and Omotade (2006) that caution is required in the administration of gluteal intramuscular injection for children

Children who had CNS infections, mainly meningitis and presented with motor disorders and abnormal muscle tone were managed during the period reviewed. This may be explained by the findings of Ali [1995], which showed that $40 \%$ of children with neonatal meningitis develop obvious neurological problems. Also in this study, Poliomyelitis was categorized under CNS 
infections and $8(1.7 \%)$ cases were managed. This low prevalence could be attributed to the decline in Poliomyelitis resulting from the mass immunization initiative for the eradication of the condition (WHO, 1997).

Down syndrome accounted for $2.2 \%$ of cases reviewed. Although children with Down syndrome experience postural and movement abnormalities which benefit from physiotherapy (Lauteglager et al, 1998), the low prevalence seen in this study may be due however to the low prevalence of the condition in general population.

Paediatric neurological conditions still constitute health problems in developing countries (Hussain et al, 1991). It is therefore important that more resources be deployed (human and material) for the prevention of the potentially preventable neurological conditions and for appropriate and effective management.

\section{REFERENCES}

Al Naquib N (1988) Neurodevelopmental problems in children in Riyadh Saudi Arabia: 1 year experience in a family practice centre. Journal of Tropical pediatrics 34, $294-300$.

Ali, Z [1995] Neonatal meningitis: A 3 year retrospective study at the Mount hope women's hospital Trinidad west Indies. Journal of Tropical Pediatrics 41,109-11.

Edwards S. (2002) Abnormal tone and movement as a result of neurologic Impairment considerations for treatment. In Edwards S (2002) Neurological Physiotherapy: A problem solving approach $2^{\text {nd }}$ ed. Churchill Livingstone, New Delhi. 89 -111.

Grether J.K, Cummins S.K end Nelson KB (1992) The California cerebral palsy project. Paediatric and Perinatal Epidemiology 6, 339-351.

Hamzat TK and Omotade TT. (2006) Acute flaccid paralysis : a five - year review of cases managed by physiotherapy at the university college Hospital Ibadan. African Journal of Health Sciences 13: 28-32.
Hayes MS, Mc Ewen IR, and Lovett D (1999) Next step: Survey of pediatric physical therapists educational needs and perceptions of motor control, motor development and motor learning as they relate to services for children with developmental disabilities Pediatric Physical Therapy 11, 164 - 182

Lauteglager PEM, Vermeer A and Helders PSM (1998) Disturbances in the motor behavior of children with down's syndrome: the need for a theoretical framework. Physiotherapy 84, 5-13.

Lebel MH and McCracken GH (1989) Delayed cerebrospinal fluid sterilization and adverse outcome of bacterial meningitis in infants and children Pediatrics 83: 161-167.

Logigian MK (1989) Introduction. In Logigian MK and Ward JD (eds) (1989) Pediatric Rehabilitation. Little, Brown and Company London pg 1-22.

Lopez PM, Stone D and Harper G. (1995) Epidemiology of down's syndrome in a Scottish city. Paediatric and Perinatal Epidemiology 9,331 -340.

Michaud LD (2004) Prescribing therapy services for children with motor disabilities Pediatrics 113, 18361838.

Milles M and Frizzel Y (1990) Handling the cerebral Palsied child : multi-level skill transfer in Pakistan. Physiotherapy 76, $183-186$.

Royal College of Paediatrics and Child Health [2004]. Commissioning Tertiary and specialized services for children and young people. Accessed from: URL: http://www.rcoa.ac.uk/ apagbi/docs/ RCPCHTertiary.pdf, 2006April24.12.00 noon.

Steyer - Acevedo [1994] Physical therapy for children with cerebral palsy. In Tecklin JC [1994] Pediatric Physical Therapy JB Lippincott company, Philadelphia. 89-133

Thomson A, Skinner A and Piercy J (1999) Neurological conditions affecting children. Tidy's physiotherapy 12ed Butterworth - Heinemann Oxford 313-370.

World Health Organization (1997) Polio: The beginning of the end. WHO/EPI/GEW/97.03, CH-1211 Geneva 27, Switzerland. 